\title{
Taylor Rule in an Open Economy: Has the Conduct of Monetary Policy Changed in Turkey?
}

\author{
Assoc. Prof. Dr. Kenan Lopcu (Çukurova University, Turkey)
}

\begin{abstract}
This paper studies whether the conduct of monetary policy has changed in Turkey since 1990s by investigating structural changes in a Taylor type of policy rule. Using recently developed econometric techniques (Kejriwal and Perron, 2010), I first test whether structural breaks have occurred in the policy rule. If the tests corroborate the existence of breaks, then I test whether the relevant variables are indeed cointegrated, following Arai and Kurozumi (2007) and Kejriwal (2008). Finally, I estimate the Taylor-type policy rules for each era to see how the conduct of monetary policy may have changed over time. Contrary to a common belief, the results indicate that no significant changes have occurred in the conduct of monetary policy in Turkey since the 1990s.
\end{abstract}

\section{Introduction}

There has been a renewed interest in the conduct of monetary policy in the last quarter century. After almost exclusive focus on nonmonetary factors in explaining business cycles in the 1970s and 1980s, a great deal of empirical literature since the late 1980s has documented that monetary policy significantly influences short-term real economic activity. Additionally, the theoretical literature used for policy analysis improved significantly, giving birth to a new loose consensus called the New Neo-Classical Synthesis or New Keynesian Macroeconomic Model. The New Neo-Classical Synthesis incorporates the techniques of dynamic general equilibrium models from the Real Business Cycle Theory, intertemporal optimization and rational expectations hypothesis of the New Classical Economics and the Real Business Cycle Theory, and nominal and real rigidities from the New Keynesian Economics. The crucial element in the new consensus is that the firm's price setting behavior causes some temporary nominal rigidities thus enabling monetary policy to have real effects in the short run while maintaining the neutrality of money in the long run (Clarida et. al, 1999). Hence, there is now an agreement among macroeconomists that monetary policy is in fact important for the aggregate economic activity in the short run. For the choice of policy rules, Taylor type rules which call for the adjustment of the short run interest rate in response to deviations in output and expected inflation from their target levels are commonly used in the literature. Because the exchange rate is an important component of the monetary policy transmission mechanism in open economies, the TL/\$ exchange rate is also included in the analysis to check the robustness of the results.

From the mid 1970s through the early 2000s, Turkey experienced high and volatile inflation along with two severe recessions $(1994,2001)$ and sharp devaluations. Since the early 2000s, however, inflation has declined gradually while the Turkish Lira has had a tendency to appreciate and output growth has been relatively steady. Meanwhile, the Central Bank of the Republic of Turkey (CBRT) has adopted first implicit (2002-2006), and then explicit (since 2006) inflation targeting policies. Using recently developed econometric techniques (Kejriwal and Perron, 2010) this paper attempts to identify whether structural breaks occur in the relationship between the interest rate and the relevant variables. If the tests corroborate the existence of structural breaks, then I test whether the variables are indeed cointegrated, following Arai and Kurozumi (2007) and Kejriwal (2008). Finally, I estimate the Taylor-type policy rules for each era to see how the conduct of monetary policy may have changed in Turkey since the 1990s.

The analysis indicates that no significant changes took place in the conduct of the monetary policy in Turkey since the 1990s. In particular, no significant change in the response of the CBRT to the expected inflation is observed. Response to the output gap is either not significant or has the wrong sign in all eras, and inclusion of the exchange rate in the analysis does not change the results. .

\section{Empirical Strategy}

The Taylor rule relates the short run interest rate to inflationary expectations and the output gap. For empirical implementation, I start with the following basic model:

$$
R_{t}=c+\alpha_{1} E_{t} \inf _{t+1}+\alpha_{2} G A P_{t}+u_{t}
$$

where $c$ refers to the regression intercept, and $E_{t} i n f_{t+1}$ and $G A P_{t}$ stand for the expected inflation for time $\mathrm{t}+1$ as of time $t$ and deviation of current output from its trend respectively. I start the empirical analysis by investigating the order of integration of the variables, using the ADF (Dickey and Fuller, 1981) and KPSS (Kwiatkowski, et. al, 1992) tests. Next, to assess the stability of the relationship between the interest rate, expected inflation and the output gap, I use the tests proposed by Kejriwal and Perron (2010) involving both I(1) and I(0) but cointegrated variables with multiple structural changes of unknown timing in regression models. If the Kejriwal-Perron tests 
corroborate the existence of structural breaks, then I verify whether the variables are indeed cointegrated by cointegration tests following Kejriwal (2008), which are based on the extension of the one-break cointegration tests developed by Aria and Kurozumi (2007) (A-K henceforth) with a null of cointegration. Finally, I estimate the model with breaks to investigate how the policy rule may have altered over time.

\subsection{Structural Break Tests}

Kejriwal and Perron (2010) considered three types of statistics for testing multiple breaks. The first is the subWald test, $S u b F$, of the null hypothesis of no structural break against the alternative hypothesis of $k$ breaks. The second test, a double maximum test called UDmax, checks the null hypothesis of no structural breaks against the alternative of an unknown number of breaks. The third test involves a sequential procedure $(S E Q)$ that analyzes the null hypothesis of $k$ breaks against the alternative hypothesis of $k+1$ breaks. A useful strategy, then, is to use significant SubF and UDmax tests to decide if breaks exist and subsequently utilize the sequential procedure to determine the number of breaks (Kejriwal, 2008). As an alternative, the number of breaks can also be determined by using the Bayesian information criterion (BIC) suggested by Yao (1988) and the modified Schwarz criterion proposed by Liu et al. (1997) (LWZ).

\subsection{Tests for Cointegration with Multiple Breaks}

Kejriwal and Perron (2010) showed that the structural change tests they proposed have good size and power properties. In addition, as pointed out in Kejriwal (2008) structural change tests also have power against a purely spurious regression. This means that when the cointegrating relation is unstable, the conventional cointegration tests are biased towards the non-rejection of the null of no cointegration. Hence, cointegration analysis should consider the structural changes. Structural change tests developed by Gregory and Hansen (G-H) (1996) under the null of no cointegration have power against the alternative of a single break, and therefore can have a low power if there is more than a single break. Finally, if the primary concern is cointegration with structural breaks, the null of cointegration is a more natural choice from the viewpoint of conventional hypothesis testing (Kejriwal, 2008).

To avoid these problems, Kejriwal (2008) extends the cointegration test with the known or unknown one structural break tests proposed by A-K to analyze multiple structural breaks under the null of cointegration. The A-K test for cointegration follows $\mathrm{G}-\mathrm{H}$ regime shift model $(\mathrm{C} / \mathrm{S})$ but the null is cointegration with a structural break. The dummy variable that indicates the structural change is defined as in G-H (1996, p.102-103):

$$
D_{t \tau}= \begin{cases}O \text { if } & t \leq[T . \tau] \\ 1 \text { if } & t>[T . \tau]\end{cases}
$$

Where the unknown parameter $\tau \in(0,1)$ denotes the timing of the structural change point and [ ] denotes the integer part. Then, the $\mathrm{G}-\mathrm{H}$ regime shift model is

$$
y_{1 t}=\mu_{1}+\mu_{2} D_{t \tau}+\alpha_{1}^{T} y_{2 t}+\alpha_{2}^{T} y_{2 t} D_{t \tau}+e_{t}, \quad t=1 \ldots, T .
$$

Where $y_{1 t}$ is the $\mathrm{I}(1)$ dependent variable, $y_{2 t}$ the vector of $\mathrm{I}(1)$ regressors and $\alpha_{1}^{T}, \alpha_{2}^{T}$ are the row vectors of coefficients. Random term $e_{t}$ is given by

$$
e_{t}=\gamma_{t}+v_{t}, \quad \gamma_{t}=\gamma_{t-1}+u_{t}, \quad \text { and } \gamma_{0}=0
$$

Where $u_{t}$ is i.i.d. $\left(0, \sigma_{u}^{2}\right)$ and independent of $v_{t}$. Under the null of cointegration with a structural break $e_{t}=v_{t}$ is stationary, i.e. $\sigma_{u}^{2}=0$. Kejriwal (2008) augments the above model for multiple structural breaks. Hence, the model for each of the $k+1$ regime becomes

$$
y_{t}=c_{i}+z_{t}^{\prime} \beta_{i}+u_{t} \quad \text { if } T_{i-1}<t \leq T_{i} \quad \text { for } i=1, . . k+1 .
$$

Where $k$ is the number of breaks, $z_{t}$ is a vector of I (1) regressors, given by $z_{t}=z_{t-1}+u_{z t}, y_{t}$ is the dependent I (1) variable, and by convention, $T_{0}=0$ and $T_{k+1}=T$. Augmenting the above regression model to deal with the simultaneity bias, the Dynamic Ordinary Least Squares (DOLS) is used, adding the leads and lags of the first differences of the regressors.

$$
y_{t}=c_{i}+z_{t}^{\prime} \beta_{i}+\sum_{j=-l_{T}}^{l_{T}} \Delta z_{t-j}^{\prime} \Pi_{j}+u_{t}^{*} \quad \text { if } T_{i-1}<t \leq T_{i} \quad \text { for } i=1, \ldots, k+1 .
$$

The test statistic for $k$ breaks, then, is given by:

$$
\tilde{V}_{k}(\hat{\lambda})=\frac{T^{-2} \sum_{t=1}^{T} S_{k}(\hat{\lambda})^{2}}{\Omega_{11}}
$$


Where $\Omega_{11}$ is a consistent estimation of the long run variance of $u_{t}^{*}, \hat{\lambda}=\left(\hat{T}_{1} / T, \ldots \ldots, \hat{T}_{k} / T\right)$, $S_{k}(\hat{\lambda})=\sum_{i=1}^{t} \hat{u}_{i \hat{\lambda}}^{*}$, and $\hat{u}_{i \hat{\lambda}}^{*}$ represents the residuals from the augmented model above. The break points $\hat{T}_{1}, \ldots . \hat{T}_{k}$ are obtained by minimizing the sum of squared residuals. The above test statistics are compared with the critical values for multiple breaks generated by the author, modifying the programs developed for Kejriwal (2008). The critical values change depending on the number of regressors and breaks incolved and the timings of the breaks. Further, as the model studied in the paper involves an $\mathrm{I}(0)$ regressor (GAP) the simulations for critical values modified by the author accordingly, generating an $\mathrm{I}(0)$ regrressor while setting $e_{t}=v_{t}$ under the null.

\section{Data}

The data set is quarterly and covers the period from 1990:Q1 to 2013:Q4. The interest rate series is from the Undersecretariat of Treasury. It is the annual percentage rate on the monthly treasury discounted auctions weighted by quantity and converted to quarterly. The output gap is obtained by the subtracting the GDP trend from the natural logarithm of actual GDP. To obtain the GDP trend, the LOG-GDP series is seasonally adjusted by $\mathrm{X}-12$, and then, the Hodrick-Prescott (H-P) filter is applied to the seasonally adjusted series. GDP series is in 1998 constant prices and obtained from the CBRT. For 1990-1998, it is calculated using the growth rates for GDP in 1987 constant prices. The inflation rate is calculated from the 2005 based harmonized indices of consumer prices, expressed annually and from the International Financial Statistics (IFS). Finally, the proxy for the exchange rate is the TL/ $\$$ buying rate and from the CBRT.

\section{Empirical Results}

In order to scrutinize the integrating level of variables, the $A D F$ and KPSS unit root tests are employed. Table 1 presents the results. According to the $A D F$ tests in Table 1 for all the variables except $G A P$ the null of nonstationary in levels cannot be rejected at any conventional significance level. KPSS tests also corroborate these results, while both tests provide evidence that the first differences of the variables are stationary. Hence, I conclude that the variables used in the study except GAP are integrated order of one, I (1) at levels.

\begin{tabular}{|c|c|c|c|c|c|c|c|c|c|c|}
\hline \multirow[b]{3}{*}{ Variables } & \multicolumn{8}{|c|}{ ADF } & \multirow{2}{*}{\multicolumn{2}{|c|}{ KPSS }} \\
\hline & \multicolumn{3}{|c|}{ Model A } & \multicolumn{3}{|c|}{ Model B } & \multicolumn{2}{|c|}{ Model C } & & \\
\hline & $k$ & $t$ & $\phi_{3}$ & $k$ & $t$ & $\phi_{1}$ & $k$ & $t$ & $\eta_{u}$ & $\eta_{\tau}$ \\
\hline$G A P$ & 3 & $-5.49^{* * *}$ & $15.11^{* *}$ & 3 & $-5.52^{* * *}$ & $15.28^{* * *}$ & 4 & $-5.56^{* *}$ & 0.04 & 0.04 \\
\hline $\operatorname{Inf}$ & 8 & -2.16 & 2.53 & 8 & -0.34 & 0.73 & 8 & -1.16 & $0.99^{* *}$ & $0.17^{*}$ \\
\hline Int & 5 & -2.65 & 4.21 & 5 & -0.50 & 0.34 & 5 & -0.83 & $0.86^{* *}$ & $0.20^{*}$ \\
\hline$d G A P$ & 3 & $-6.52^{* *}$ & $21.42^{* *}$ & 3 & $-6.59^{* *}$ & $21.71^{* *}$ & 3 & $-6.63^{* *}$ & 0.03 & 0.02 \\
\hline $\operatorname{dinf}$ & 7 & $-4.12^{* *}$ & $8.50^{* * *}$ & 4 & $-4.08^{* *}$ & $8.32^{* *}$ & 7 & $-3.97^{* *}$ & 0.08 & 0.07 \\
\hline dint & 4 & $-6.78^{* *}$ & $23.06^{* *}$ & 4 & $-6.63^{* *}$ & $21.98^{* *}$ & 4 & $-6.64^{*}$ & 0.20 & 0.10 \\
\hline \multicolumn{2}{|c|}{ Critical (**) \% 1} & -4.06 & 8.73 & & 3.50 & 6.70 & & -2.59 & 0.74 & 0.21 \\
\hline \multirow[t]{2}{*}{ Values } & $\% 5$ & -3.46 & 6.49 & & 2.89 & 4.71 & & -1.95 & 0.46 & 0.14 \\
\hline & $\% 10$ & -3.15 & 5.47 & & 2.58 & 3.86 & & -1.61 & 0.34 & 0.11 \\
\hline \multicolumn{11}{|c|}{$\begin{array}{l}\text { Models } \mathrm{A}, \mathrm{B}, \mathrm{C} \text { for the } A D F \text { tests include a constant and a linear trend, a constant, and none, } \\
\text { respectively; and } k \text { denotes the number of lags. Lags are selected according to } t \text {, allowing a maximum } \\
\text { number of } 8 \text { lags. The bandwidth length for the KPSS tests is } T^{(1 / 3)} \text {. }\end{array}$} \\
\hline
\end{tabular}

Table 1. ADF and KPSS Unit Root Tests

As the next step, I test the null of no structural change in the long-run relationship. The results obtained are reported in Table 2. Overall the tests offer mixed evidence in favor of the presence of break(s). In particular, the $S u b F, U D$ max tests and the $L W Z$ offer no evidence of break. Sequential test, on the other hand, cannot reject the null of one break against the alternative hypothesis of two breaks, but reject the null of two breaks in favor of three breaks. Bai and Perron (2006) suggest that when the parameter values change in such a way that the first and the third regimes are identical, the sequential procedure select no breaks. Further, SubF(1) and UDMax test statistics in Table 2 are fairly close to the $10 \%$ crtical values of 11.69 and 11.99 respectively. Finally, the BIC suggest one break.

It is important to note the break dates selected by the $B I C$ and the sequential test, $S E Q_{T}(3 / 2), 1994: \mathrm{Q} 2$, 1999:Q4 and 2007:Q2 coincide with the period of two crises in Turkey and the global financial crisis of 2007. The mid-nineties and early 2000s were the periods of financial and economic crises in Turkey, in which the Turkish lira lost its value sharply, interest rates sky-rocketed, and inflation and unemployment began to soar. The 
Turkish GDP was also reduced significantly in these crises periods. Hence, it's worth investigating these three potential breaks.

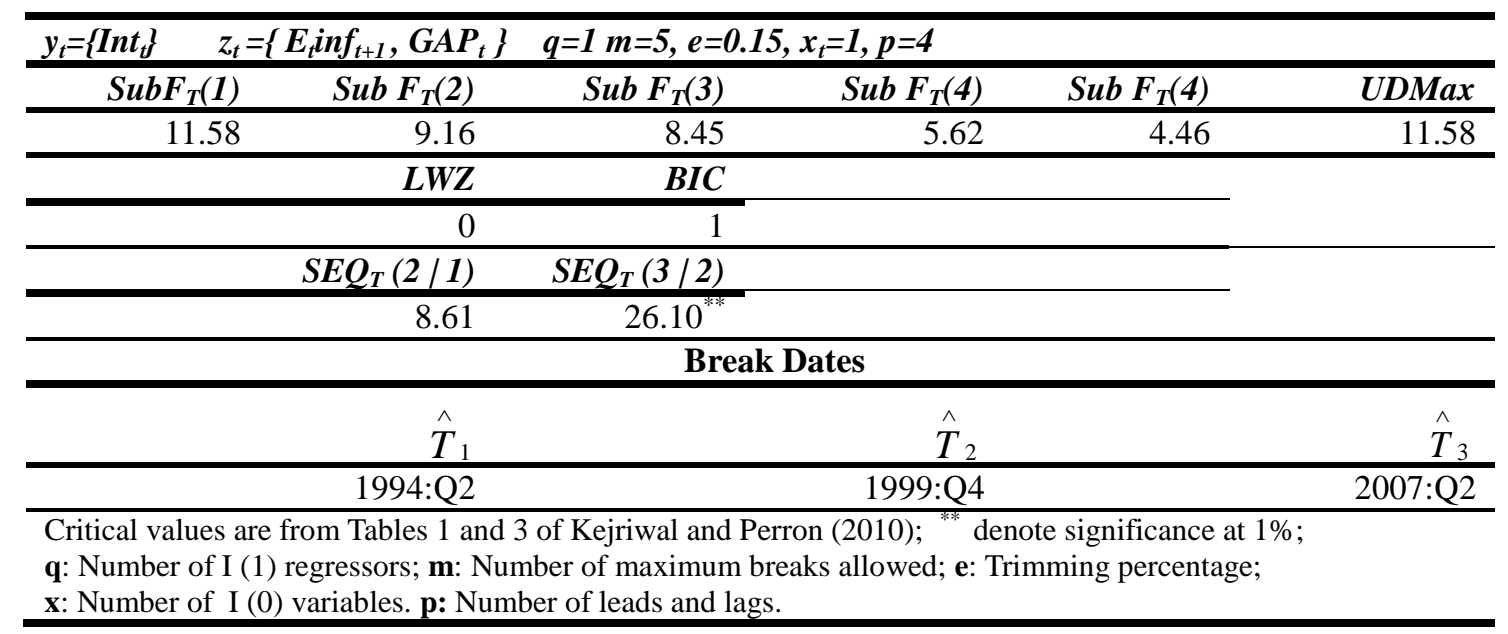

Table 2. Kejriwal-Perron Tests for Testing Multiple Structural Breaks (C/S Model)

\begin{tabular}{|c|c|c|c|c|c|c|c|c|}
\hline \multicolumn{2}{|l|}{$y_{t}=\left\{\right.$ Int $\left._{t}\right\}$} & $\tilde{V}_{k}(\hat{\lambda})$ & $\hat{\lambda}_{1}$ & $\hat{\lambda}_{2}$ & $\hat{\lambda}_{3}$ & $\hat{T}_{1}$ & $\hat{T}_{2}$ & $\hat{T}_{3}$ \\
\hline \multicolumn{2}{|c|}{$z_{t}=\left\{E_{t} \inf _{t+1}, G A P_{t}\right\}$} & 0.076 & 0.20 & & & 1994:Q2 & & \\
\hline Critical Values & $\begin{array}{r}* * \% 1 \\
* \% 5 \\
\# \% 10\end{array}$ & $\begin{array}{l}0.369 \\
0.209 \\
0.151\end{array}$ & & & & & & \\
\hline \multicolumn{2}{|c|}{$z_{t}=\left\{\right.$ Einflation $\left._{t+1}, \boldsymbol{G A P}_{t}\right\}$} & $\mathbf{0 . 0 1 0}^{\#}$ & 0.20 & 0.45 & & 1994:Q2 & 1999:Q4 & \\
\hline Critical Values & $\begin{array}{r}* * \% 1 \\
* \% 5 \\
\# \% 10\end{array}$ & $\begin{array}{l}0.163 \\
0.101 \\
0.080\end{array}$ & & & & & & \\
\hline \multicolumn{2}{|c|}{$z_{t}=\left\{E_{t} \inf _{t+1}, G A P_{t}\right\}$} & 0.036 & 0.20 & 0.45 & 0.81 & 1994:Q2 & 1999:Q4 & 2007:Q2 \\
\hline Critical Values & $\begin{array}{r}* * \% 1 \\
* \% 5 \\
\# \% 10\end{array}$ & $\begin{array}{l}0.086 \\
0.059 \\
0.050\end{array}$ & & & & & & \\
\hline
\end{tabular}

Critical values are obtained by simulations using 100 steps and 2500 replications.

Table 3. Aria-Kurozumi Single Break and Kejriwal Multiple Breaks Cointegration Tests (C/S Model)

\begin{tabular}{|c|c|c|c|c|c|c|}
\hline \multicolumn{2}{|c|}{$\boldsymbol{y}_{\boldsymbol{t}}=\left\{\boldsymbol{I n t}_{t}\right\}$} & \multicolumn{2}{|c|}{$\underline{z}_{t}=\left\{\boldsymbol{E}_{t} \boldsymbol{i n f} \boldsymbol{f}_{t+1}, \boldsymbol{G A P} \boldsymbol{P}_{t}\right\}$} & \multicolumn{2}{|c|}{ 994:Q2; 1999:Q4; 2007:Q2 } & \\
\hline \multicolumn{7}{|c|}{ Break Dates } \\
\hline & 1994:Q2 & & 1994:Q & 999:Q4 & 1994:Q2; 1 & $4 ; 2007: Q 2$ \\
\hline & Coefficient & $\begin{array}{l}\text { P-Value } \\
\end{array}$ & Coefficient & P-Value & Coefficient & P-Value \\
\hline$c_{1}$ & -0.91 & 0.00 & -0.85 & 0.00 & -0.85 & 0.00 \\
\hline$\varphi_{11}$ & 2.51 & 0.00 & 2.43 & 0.00 & 2.43 & 0.00 \\
\hline$\varphi_{12}$ & -0.87 & 0.26 & -0.63 & 0.39 & -0.71 & 0.29 \\
\hline$c_{2}$ & 0.05 & 0.12 & 0.73 & 0.00 & 0.72 & 0.00 \\
\hline$\varphi_{21}$ & 1.40 & 0.00 & 0.64 & 0.01 & 0.65 & 0.01 \\
\hline$\varphi_{22}$ & 0.10 & 0.87 & 2.27 & 0.03 & 2.19 & 0.03 \\
\hline$c_{3}$ & & & 0.06 & 0.08 & 0.21 & 0.00 \\
\hline$\varphi_{31}$ & & & 1.27 & 0.00 & 0.87 & 0.00 \\
\hline$\varphi_{32}$ & & & -0.48 & 0.45 & -3.27 & 0.00 \\
\hline$c_{4}$ & & & & & -0.02 & 0.89 \\
\hline$\varphi_{41}$ & & & & & 1.67 & 0.39 \\
\hline$\varphi_{42}$ & & & & & 0.24 & 0.78 \\
\hline
\end{tabular}

Table 4. Estimated Regressions with a Single and Multiple Structural Breaks (C/S Model).

The following step is to confirm the existence of cointegration among the interest rate, expected inflation and the output gap to ensure that the "rejection of stability" is indeed derived from the existence of a cointegration relationship with breaks, and not from a purely spurious regression. In this context, A-K cointegration test for a 
single break and cointegration tests with multiple breaks based on the A-K framework, using the break dates selected by the sequential test $S E Q_{T}(3 / 2)$ and the BIC, are performed.

The results in Table 3 indicate that the null of cointegration cannot be rejected at any conventional significance levels for one and three breaks cases, and can only be rejected at the $10 \%$ significance level for the two break case. As the final step I estimate the above models for which there is evidence of cointegration, and compare the coefficients for the sub periods to see how the cointegration relationship may have changed over time. Table 4 presents the results.

\begin{tabular}{|c|c|c|c|c|c|c|}
\hline \multicolumn{2}{|c|}{$y_{t}=\left\{\right.$ Int $\left._{t}\right\}$} & \multicolumn{2}{|c|}{ 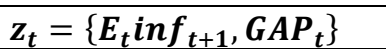 } & \multicolumn{2}{|c|}{ 94:Q2; 1999:Q4; 2007:Q2 } & \\
\hline \multicolumn{7}{|c|}{ Break Dates } \\
\hline \multicolumn{3}{|c|}{ 1994:Q2 } & \multicolumn{2}{|c|}{ 1994:Q2；1999:Q4 } & \multicolumn{2}{|c|}{$1994: Q 2 ; 1999: Q 4 ; 2007: \mathrm{Q}^{2}$} \\
\hline & Coefficient & $\begin{array}{l}\text { P-Value } \\
\end{array}$ & Coefficient & P-Value & Coefficient & P-Value \\
\hline$\delta$ & 1.14 & 0.00 & 1.22 & 0.00 & 1.24 & 0.00 \\
\hline$c_{1}$ & -0.07 & 0.80 & 0.06 & 0.83 & 0.08 & 0.74 \\
\hline$\varphi_{11}$ & 1.24 & 0.00 & 1.06 & 0.01 & 1.02 & 0.01 \\
\hline$\varphi_{12}$ & -0.30 & 0.67 & -0.07 & 0.91 & -0.15 & 0.80 \\
\hline$\delta_{2}$ & 0.13 & 0.66 & 0.80 & 0.01 & 0.78 & 0.01 \\
\hline$\alpha_{21}$ & 0.14 & 0.75 & -0.60 & 0.15 & -0.56 & 0.14 \\
\hline$\alpha_{22}$ & -0.24 & 0.78 & 0.80 & 0.48 & 0.76 & 0.46 \\
\hline$\delta_{3}$ & & & 0.00 & 0.99 & 0.15 & 0.55 \\
\hline$\alpha_{31}$ & & & 0.19 & 0.64 & -0.19 & 0.62 \\
\hline$\alpha_{32}$ & & & -0.79 & 0.35 & -3.43 & 0.00 \\
\hline$\delta_{4}$ & & & & & -0.09 & 0.75 \\
\hline$\alpha_{41}$ & & & & & 0.43 & 0.80 \\
\hline$\alpha_{42}$ & 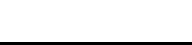 & & & & -0.09 & 0.92 \\
\hline
\end{tabular}

Table 5. Estimated Regressions with a Single and Multiple Structural Breaks (C/S Model).

At the first glance, the response of the interest rate to expected inflation and the output seem to be different in each regime. In particular, the response of the central bank to the inflationary expectations is consistent with a priori expectations but not significant in the last regime, the period in which the CBRT has applied explicit inflation targeting policies. Taking the first regime as the base and testing whether the regime differences are significant, the second and third regimes turn out to be completely dissimilar to the first regime. For the last regime, on the other hand, only the intercept parameter turns out to be significantly different from the first regime.

The differences among the regimes, however, appear to be driven largely by a single outlier in 1994:Q2 (See Figure 1 in the Appendix). Including a dummy variable which takes a value of 1 only for 1994:Q2, reverses the results completely. Table 5 presents the results regarding the significance of differences between the first and the other regimes. According to the results in Table 5, there is no significant difference between the first and the second regime in the one break case. For the two structural breaks case, the first and the third regimes turn out to be identical while the second regime differs significantly only in the intercept. Finally, the first and the last regimes are identical when three structural breaks are accounted for while the second and third regimes are different only in the intercept and the coefficient of the output gap with the wrong sign, respectively.

Overall, the findings in Table 5 indicate that the reaction function of the CBRT has not changed significantly since the 1990s. In particular the response of the interest rate to inflationary expectations appears to be identical for all cases in all the regimes. Including the TL/ exchange rate in the analysis, do not improve the model. Some coefficients turn out be insignificant or gets the wrong sign. For example, for the three breaks case, inflationary expectations turns out to be significant only in the third regime. Hence, it is likely that the policy rule has been stable since the 1990s.

In light of the results and the discussion above and the mixed I(1), I(0) nature of the regressors in the model, I use Peseran et al.. (2001) bounds testing approach to investigate the existence of long run relationship between the interest rate, inflationary expectations and the output gap for the entire sample period. In the bounds testing approaches, first, the appropriate lag length is selected from a vector auto regressive (VAR) model. Then, the test for the existence of a long run level relationship is performed. Once the level relationship is verified, the long run relationship as well as the error correction representation can be estimated, allowing the lags to be different for each regressor. Table 6 presents the findings.

Table 6 reveals that the CBRT reacts to inflationary expectations, but the output gap has the wrong sign and is not significant. The error correction term indicates that $87 \%$ of the deviations from the long run level relationship vanish after a quarter. For the sake of comparison, I apply the bounds testing approach for the post 
2000 era. The F test rejects the null of no level relationship at all conventional significance levels. The output gap coefficient becomes marginally significant at 5\% level, the intercept term becomes negative but remains insignificant and the effect of inflationary expectations increase slightly. However, the error correction term decrease in absolute value, indicating just over $30 \%$ of the deviations from the level relationship vanish after a quarter.

\begin{tabular}{|c|c|c|c|c|}
\hline \multicolumn{3}{|c|}{ Lag Length Selection for VAR } & \multicolumn{2}{|l|}{ F Statistic } \\
\hline $\mathrm{k}$ & AIC & SIC & $9.25^{* * * *}$ & \\
\hline 1 & 26.75 & 255.46 & Critical $\quad(* *) \% 1$ & $5.32-6.45$ \\
\hline 2 & 270.64 & 245.63 & $(* *) \% 5$ & $3.95-4.94$ \\
\hline 3 & 280.68 & 244.95 & (\#) $\% 10$ & $3.27-4.20$ \\
\hline 4 & 283.89 & 237.44 & & \\
\hline 5 & 289.96 & 232.80 & & \\
\hline 6 & 288.43 & 220.54 & & \\
\hline 7 & 287.12 & 208.52 & & \\
\hline 8 & 284.44 & 195.12 & & \\
\hline \multicolumn{5}{|c|}{ Estimated Long-Run Relationship Coefficients, ARDL $(2,7,1)$} \\
\hline Regressor & Coefficient & Standart Error & t - Statistic & P - Value \\
\hline constant & 0.022 & 0.034 & 0.640 & 0.524 \\
\hline$G A P$ & -0.106 & 0.527 & -0.200 & 0.842 \\
\hline Einflation & 1.407 & 0.060 & 23.447 & 0.000 \\
\hline \multicolumn{5}{|c|}{ Error Correction Representation of ARDL $(2,7,1)$} \\
\hline Regressor & Coefficient & Standart Error & $\mathbf{t}$ - Statistic & P - Value \\
\hline constant & 0.019 & 0.030 & 0.633 & 0.529 \\
\hline $\operatorname{dint}(-1)$ & 0.146 & 0.109 & 1.337 & 0.185 \\
\hline $\operatorname{dinf}$ & 0.768 & 0.267 & 2.880 & 0.005 \\
\hline $\operatorname{dinf}(-1)$ & -0.786 & 0.303 & -2.591 & 0.012 \\
\hline $\operatorname{dinf}(-2)$ & -0.932 & 0.290 & -3.215 & 0.002 \\
\hline $\operatorname{dinf}(-3)$ & -0.990 & 0.231 & -4.288 & 0.000 \\
\hline $\operatorname{dinf}(-4)$ & -0.440 & 0.286 & -1.538 & 0.129 \\
\hline $\operatorname{dinf}(-5)$ & 0.707 & 0.278 & 2.539 & 0.013 \\
\hline $\operatorname{dinf}(-6)$ & -0.542 & 0.268 & -2.029 & 0.046 \\
\hline$d G A P$ & -1.795 & 0.630 & -2.847 & 0.006 \\
\hline $\operatorname{ecm}(-1)$ & -0.871 & 0.142 & -4.150 & 0.000 \\
\hline
\end{tabular}

Table 6. Results from the ARDL Bounds Testing Approach

\section{Conclusion}

This paper studies whether the conduct of monetary policy has changed in Turkey since 1990s by investigating structural changes in a Taylor type of policy rule. Using recently developed econometric techniques (Kejriwal and Perron, 2010, Arai and Kurozumi, 2007 and Kejriwal, 2008). Structural break tests provide mixed evidence of regime changes and fail to firmly establish breaks in the monetary policy rule. Although there is a fairly strong evidence of cointegration with structural break at the suggested dates, estimated regressions indicate no significant changes has occurred in the policy rule especially when an existing outlier, 1994:Q2, is accounted for. The effect of inflationary expectations in general is consistent with the findings of other studies for Turkey such as Kesriyeli and Yalçın (1998), Aklan and Nargeleçekenler (2008) and Yıldırım et al (2010).

\section{References}

- Aklan, N. and Nargeleçekenler, M., 2008. "Taylor Kuralı: Türkiye Üzerine Bir Değerlendirme”, Ankara Üniversitesi SBF Dergisi, 63-2, p. 22-42.

- Arai, Y., Kurozumi, E., 2007. "Testing for the Null Hypothesis of Cointegration with a Structural Break," Econometric Reviews, 26-6, p. 705-739.

- Bai, J., and Perron, P., 2006. "Multiple Structural Change Models: A Simulation Analysis", in D. Corbea, S.Durlauf and B.E. Hansen (eds), Econometric Theory Practice Frontiers of Analysis Applied Research, Cambridge University Press, p. 212-237.

- Clarida,R., Gali, J. and Gertler, M., 1999. "The Science of Monetary Policy: A New Keynesian Perspective", Journal of Economic Literature, 37, p. 1661-1707. 
- $\quad$ Dickey, D.A., Fuller, W.A., 1981. "Likelihood Ratio Statics for Autoregressive Time Series with a Unit Root", Econometrica, 49, p. 1057-1072.

- Gregory, A. W. and Hansen, B. E., 1996. "Residual-Based Tests for Cointegration in Models with Regime Shifts", Journal of Econometrics, 70, p. 99-126.

- $\quad$ Kejriwal, M., 2008. "Cointegration with Structural Breaks: An Application to the Feldstein-Horioka Puzzle", Studies in Nonlinear Dynamics and Econometrics, 12-1, Article 3.

- $\quad$ Kejriwal, M. and Perron, P., 2010. "Testing for Multiple Structural Changes in Cointegrated Regression Models", American Statistical Association Journal of Business and Economic Statics, 28-4, p.503-522.

- Kesriyeli, M. and Yalçın, C. 1998. “Taylor Kuralı ve Türkiye Uygulaması Üzerine Bir Not”, Türkiye Cumhuriyet Merkez Bankası Araştırma Genel Müdürlüğü, Tartışma Tebliği No: 9802.

- $\quad$ Kwiatkowski, D., Phillips, P. C. B., Schmidt P. and Shin, Y., 1992. “Testing the Null Hypothesis of Stationarity against the Alternative of a Unit Root: How Sure are We that Economic Time Series have a Unit Root?", Journal of Econometrics, 54-1, p. 159-178

- Liu, J., Wu, S. and Zidek J. V., 1997. “On Segmented Multivariate Regression”, Statistica Sinica, 7, p. 497525.

- $\quad$ Peseran, M. H., Shin, Y. and Smith, R. J., 2001. "Bounds Testing Approaches to the Analysis of Long-Run Relationships", Journal of Applied Econometrics, 16, p. 289-326.

- Yao, Y., C., 1988. "Estimating the Number of Change Points via Schwartz Criterion”, Statistics and Probability Letters, 6, p. 181-189.

- Yildirim, E., Lopcu, K., Çakmaklı, S., and Özkan, Ö., 2010. "Yeni Keynesyen Makro Ekonomik Bir Model: Türkiye Uygulamas1.", Ege Academic Review 10-4, p. 1269-1277. 


\section{Appendix}

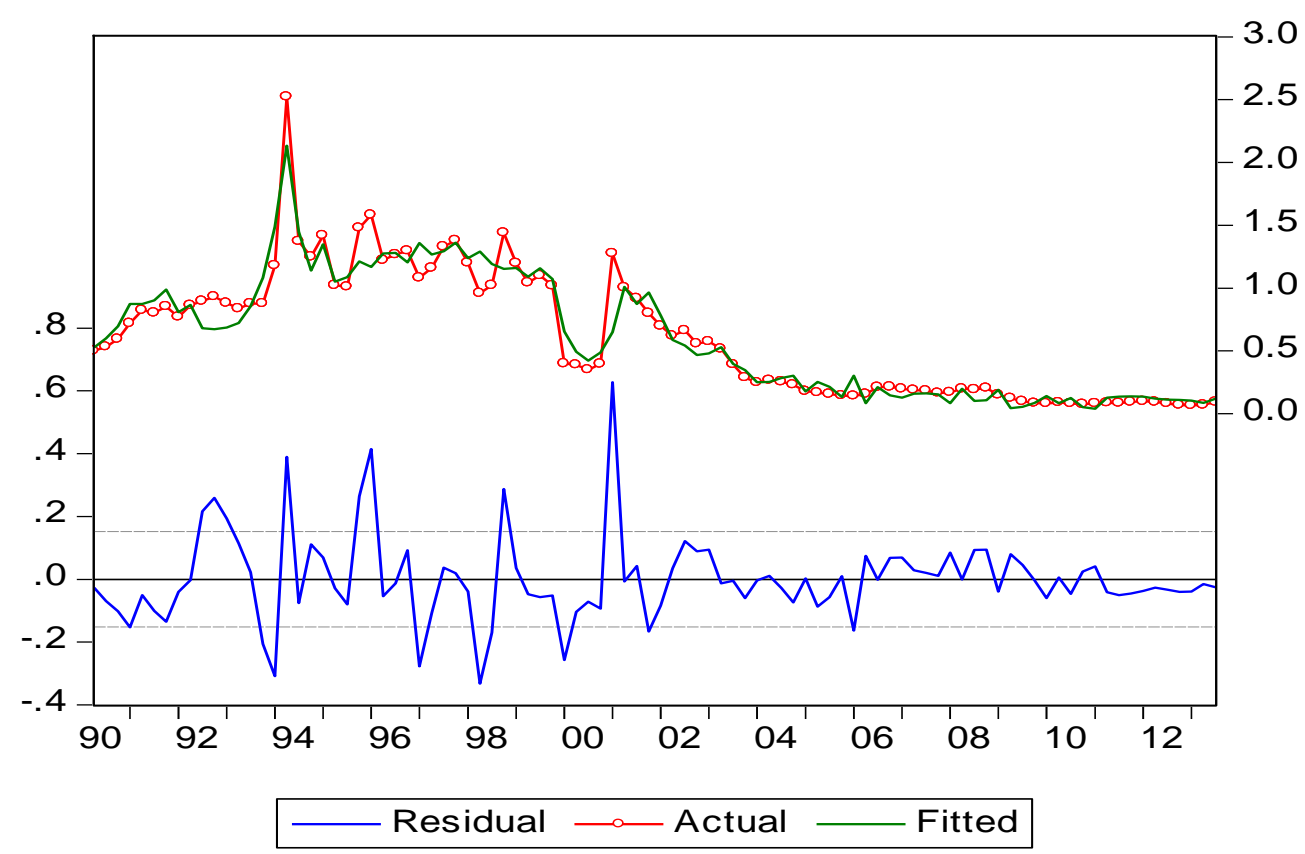

Figure 1. Actual, Fitted and Residual Values with 3 breaks Model from Table 4 